\title{
GEOFORMAS DEPOSICIONAIS NO BAIXO CURSO DO RIO TAPAIÚNA LOCALIZADO NO MUNICÍPIO DE NOVA CANÃA DO NORTE-MATO GROSSO
}

\author{
Luana Rodrigues de Carvalho ${ }^{(a)}$, Leila Nalis Paiva da Silva Andrade ${ }^{(b)}$, Claudete Silveira Damas \\ Machado $^{(\mathrm{c})}$, Andressa Damas Machado ${ }^{(\mathrm{d})}$ \\ (a) Acadêmica do curso de licenciatura em Geografia da Universidade Estadual do Estado de Mato Grosso - \\ UNEMAT, Bolsista de Iniciação Científica.Email: lunas2.rc@gmail.com \\ ${ }^{(b)}$ Professsora Assistente da Universidade do Estado de Mato Grosso-UNEMAT, Doutoranda em Ecologia e \\ Recursos Naturais pela Universidade Federal de São Carlos- UFSCar.Coordenadora do Laboratório de Pesquisa e \\ Ensino e Geomorfologia Fluvial "Antonio Christofoletti" Coordenadora de Área do Subprojeto PIBID/ Geografia / \\ Colider - Mato Grosso.Email: leilaandrade@ unemat.br \\ ${ }^{(c)}$ Acadêmica do Curso de Licenciatura em Geografia da Universidade do Estado de Mato Grosso - UNEMAT \\ Campus Universitário Vale do Teles Pires. Bolsista do Programa Institucional de Bolsas de Iniciação à \\ Docência/PIBID. E-mail: klaudete_machadotnn@ @otmail.com \\ (d) Acadêmica do Curso de Licenciatura em Geografia da Universidade do Estado de Mato Grosso - UNEMAT \\ Campus Universitário Vale do Teles Pires. Bolsista de Iniciação Científica/FAPEMAT. E-mail: \\ andressa_tna@hotmail.com
}

\section{EIXO: BACIAS HIDROGRÁFICAS E RECURSOS HÍDRICOS: ANÁLISE, PLANEJAMENTO E GESTÃO}

\section{Resumo}

O presente trabalho tem como objetivo identificar e quantificar as geoformas deposicionais no baixo curso do rio Tapaiúna situado no município de Nova Canãa do Norte, Mato Grosso.Foram realizados trabalhos de gabinete e de campo. Para elucidar a temática, foram feitas pesquisas em livros, revistas, artigos científicos e outros. O campo ocorreuem outubro de 2016, no período de estiagem, onde foram observadas as geoformas deposicionais e coletadas amostras para análise no laboratório de Ensino e Pesquisa em Geomorfologia Fluvial - Antonio Christofoletti através do método de pipetagem e peneiramento.Depois de analisadas as amostras, percebeu-se que o rio Tapaiúna, afluente do rio Teles Pires, possui capacidade de transportar sedimentos grosseiros (fundo) sendo que estes são carregados no período de cheia e depositados na margem convexa formando barras arenosas.

Palavras chave: depósitos arenosos; baixo curso; rio Tapaiúna.

\section{Introdução}

Vários autores discutem conceito de bacias hidrográficas em relação forma, processos e dinâmica. De acordo com Silva et al. (2007, p.105) "a bacia drenagem é uma área da superfície terrestre que drena água, sedimentos e materiais dissolvidos para uma saída comum, num determinado ponto (ou seção) de um canal fluvial". Para Christofoletti (1980) os rios são canais de escoamento fluvial que faz parte do ciclo hidrológico e a sua alimentação se dá através das águas superficiais e subterrâneas e possuem uma 
dinâmica fluvial natural. Portanto, uma bacia hidrográfica é resultado da interação da água com outros recursos naturais, como: rochas, solo, topografia, vegetação, relevo e clima.

Os rios, em geral, dispõem três partes segundo a declividade do relevo: trecho da montanha (fase jovem do rio); trecho de vale (maturidade); e o trecho da planície ou fase senil (baixo curso), próximo a foz. Nesta localidade, o poder erosivo do rio é mínimo, depositando grande parte do material transportado. O percurso é sinuoso, há presença de praias de areia e pedregulhos na parte interna das curvas. $\mathrm{O}$ desgaste lateral supera o vertical, as curvas podem se aproximarem uma das outras e resultar no desaparecimento da parte que as separava (POPP, 2016).

Segundo Silva et al. (2007, p. 116), "os sedimentos que chegam ao curso de água têm granulometria variada e sofrem fenômenos de transporte variados, de acordo com as condições locais de escoamento". Corroborando com discussão,Carvalho (1994 apud ANDRADE; SOUZA, 2009) expõe que "a distribuição de sedimentos através de uma seção transversal é variável de um lado para o outro, sendo mais expressa em termos de concentração. Esta é variável em função da velocidade da corrente, da disponibilidade de sedimentos e de sua granulometria".

Formação de barras arenosas(central ou lateral), em um determinado local, está relacionado com a dinâmica do rio e a sazonalidade"de um ano para outro, durante as cheias regulares, elas podem variar muito sua localização e seu tamanho. Sua gênese é composta por areia fina limpa e quartzosa, com pequenas ondulações" (GALVÃO, et al., 2014). E a ocorrência desses depósitos arenosos se dá devido à instabilidade da margem associada a ausência de vegetação ciliar e ao uso do solo (ANDRADE e SOUZA, 2009).

Portanto, as geoformas deposicionais "assumem importância porque dentro de todo o sistema representam o maior volume de sedimentos depositados numa determinada unidade de tempo" (POPP, 2016, p.169).Nesse sentido, o trabalho teve por objetivo identificar e quantificar as geoformas deposicionais no baixo curso do rio Tapaiúnasituado no município de Nova Canãa do Norte, Mato Grosso.

\section{Material e Métodos}

A unidade de análise adotada para estudoé o baixo curso do rio Tapaiúna afluente do rio Teles Pires, localizado no território de Nova Canaã do Norte - Mato Grosso.

A atividade de campo ocorreu no dia 15 de outubro de 2016. Foram selecionadas duas barras de sedimentos para coleta: barra central e uma barra lateral (esquerda). Realizou-se o reconhecimento da área, levantamento dos dados de localização (latitude e longitude), mensurou-se o tamanho da área de 
cada point bars com auxílio de trena de $20 \mathrm{~m}$ e coletaram-se amostras dos sedimentos depositados em três pontos e alturas nas barras da montante para jusante. As amostras foram armazenadas em sacolas plásticas de $1 \mathrm{~kg}$ para posterior análise em laboratório. Posteriormente, foram realizadas leituras sobre a temática em livros, artigos científicos, revistas, jornais, entre outros (GIL, 2000). Para a caracterização geoambiental (geologia, geomorfologia, solo, clima e vegetação) do baixo curso do rio Tapaiúna em questão utilizou-se dados disponibilizados no Atlas de Mato Grosso (CAMARGO, 2011).

Para verificar a composição do material dos bancos de sedimentos, foi realizada a análise granulométrica com amostras de $20 \mathrm{~g}$, pesadas em balança de precisão (marca Shimadzu - mod. AUY 220). As amostras foram mantidas por 12 horas em contato com solução de dispersante químico (NaOH 0,1 M.L-1) e, após iniciou-se o processo de agitação, (aparelho agitador de Wagner TE-160) por 10 minutos. As frações areia (grossa, média e fina), silte e argila foram determinadas pelos métodos da pipetagem e peneiramento, sendo que, a fração do silte equivale a difereça da soma da area e argila dos 20 gramas iniciais (EMBRAPA, 1997).

\section{Resultados e Discussão}

\section{Caraterização Geoambiental}

A geologia do baixo curso do rio Tapaiúna data-se da Era Arqueana e Proterozóica. Encontram-se aos seguintes grupos: Iriri: com presença de riólitos, riodacitos, andesitos, basaltos, rochas piroclásticas e ignimbritos granófiros, riebeckita granitos e granitos rapakivi;Complexo Xingu: com rochas predominantemente ortometamórficas constituídas por granitos, granodioritos, adamelitos, dioritos, anfibolitos, gnaisses ácidos e básicos, migmatitos, granulitos, com subordinados quartzitos, quartzo-micaxistos e mica-xistos; Formação Dardanelos: apresentando arenitos arcoseanos médios a grosseiros com lentes de conglomerados, subgrauvacas vulcânicas e arcóseos, e, na planície fluvial, encontramseAluviões Atuais: constituído por areias, siltes, argilas e cascalhos pertencente ao Período Quaternário da Era Cenozóica(CAMARGO, 2011).

O autor supra citado discute quea morfoestrutura da localidade pertence a Plataforma Amazônica, e as morfoesculturas presentes são classificadas como: Depressão Norte Mato-Grossense e Serra dos Caiabis. Apresenta a forma de acumulação Apf: Planície fluvial. Área aplanada resultante de acumulação fluvial, periódica ou permanentemente alagada. E a forma de dissecação Dc: Formas dissecadas com topos apresentando morfologias convexas. 
No baixo curso do rio Tapaiúnas encontram-se os seguintes tipos de solos: Podzólicos Vermelho-Amarelo distrófico Tb A moderado textura média/argilosa; Solos Litólicos distróficos A moderado textura média com substrato de rochas granítico-gnáissicas; Latossolo Vermelho-Amarelo distrófico A moderado textura argilosa; Solos Concrecionários Latossólicos distróficos A moderado textura média; Areias Quartzosas álicas A moderado; Latossolo Vermelho-Amarelo álico A moderado textura média; Solos Litólicos distróficos A moderado textura média com substrato de rochas pelíticas(CAMARGO, 2011)..

Carmargo (2001) ressalta que a altitude da localidade varia entre 300-400m, a temperatura média anual da região fica entre $24,8^{\circ} \mathrm{C}$ a $24.3^{\circ} \mathrm{C}$, com pluviosidade anual de 2000 a $2300 \mathrm{~mm}$, sendo que, o excesso encontra-se entre os meses de novembro a abril. As formações de vegetais características são: Savana Arborizada ou Cerrado; Floresta Estacional/Savana; Formações Secundárias (remasnescentes de formações naturais, ocorrencia associada às áreas de uso agropecúario) e a ausência dessas formações é indício de usos antrópicos (agricultura, pecuária, extrativismo, usos urbanos e reflorestamento).

\section{Caracterização da área}

A barra arenosa central com altitude de $257 \mathrm{~m}$ e área de $185.64 \mathrm{~m}^{2}$ fica a jusante de uma feição

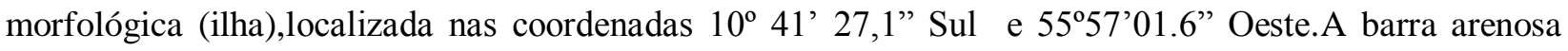
lateral esquerda (margem convexa),com altitude de $236 \mathrm{~m}$ e área de $731.4 \mathrm{~m}^{2}$ encontra-se nas coordenadas

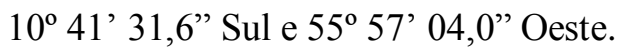

Essas geoformas deposicionais são comuns em canais meândricos, em que, "os rios descrevem curvas sinuosas, largas, harmoniosas e semelhantes entre si, através de um trabalho contínuo de escavação na margem côncava (ponto de maior velocidade da corrente) e de deposição na margem convexa (ponto de menor velocidade)" (CHRISTOFOLETTI, 1980, p. 88).

Em análises, notou-se que em ambas barras não há areia grossa e média, somente areia fina, sendo de grande percentual ao comparar com a argila e silteA composição de silte nas duas barras se concentra, na maioria dos pontos, nas maiores alturas das barras, como exemplo: na amostra coletada da altura $1.20 \mathrm{~m}$ da barra lateral esquerda (centro), é perceptivel a porcentagem de silte (12\%), sendo que, na altura de 30 cm do mesmo ponto não há presença da composição. Portanto, as amostras do material coletado nas alturas menores, próximas a lámina d'água, apresentaram em todos os pontos, porcentagens maiores que 90\% da composição de material grosseiro, especificamente, areia fina (excessão na altura menor da barra central (centro))(Tabela 1). 


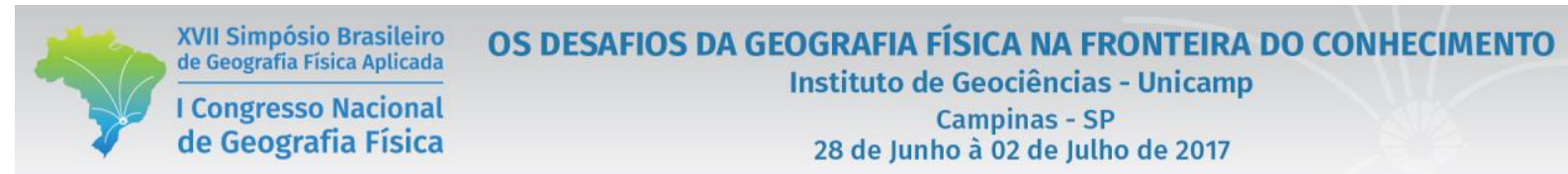

Tabela 1-Sedimentos - Barra Lateral e Central

\begin{tabular}{|c|c|c|c|c|c|}
\hline \multirow{2}{*}{ Barra } & \multirow{2}{*}{ Altura da Barra (m) } & \multirow{2}{*}{ Área $\left(\mathbf{m}^{2}\right)$} & \multicolumn{3}{|c|}{ Deposição(\%) } \\
\hline & & & Areia Fina & Argila & Silte \\
\hline \multirow{3}{*}{ Lateral Esquerda (Montante) } & 1.0 & \multirow{3}{*}{731.4} & 95.4 & 0.6 & 4 \\
\hline & 0.55 & & 98.8 & 0.9 & 0.3 \\
\hline & 0.16 & & 98.3 & 0.5 & 1.2 \\
\hline \multirow{3}{*}{ Lateral Esquerda (Centro) } & 1.20 & \multirow{3}{*}{731.4} & 87 & 1 & 12 \\
\hline & 0.86 & & 97.1 & 0.5 & 2.4 \\
\hline & 0.30 & & 99.6 & 0.4 & 0 \\
\hline \multirow{3}{*}{ Lateral Esquerda (Jusante) } & 0.46 & \multirow{3}{*}{731.4} & 85 & 0.5 & 14.5 \\
\hline & 0.25 & & 93.8 & 0.6 & 5.6 \\
\hline & 0.09 & & 99 & 0.2 & 0.8 \\
\hline \multirow{3}{*}{ Central (Montante) } & 0.33 & \multirow{3}{*}{185.64} & 93.4 & 0.6 & 6 \\
\hline & 0.25 & & 74.7 & 1.4 & 23.9 \\
\hline & 0.15 & & 86.7 & 0.8 & 12.4 \\
\hline \multirow[t]{3}{*}{ Central (Centro) } & 0.62 & \multirow{3}{*}{185.64} & 89 & 0.7 & 10.2 \\
\hline & 0.38 & & 95 & 0.5 & 4.5 \\
\hline & 0.12 & & 93.5 & 0.7 & 5.8 \\
\hline \multirow[t]{3}{*}{ Central (Jusante) } & 0.14 & \multirow{3}{*}{185.64} & 95.2 & 0.3 & 4.5 \\
\hline & 0.14 & & 96.2 & 0.3 & 3.5 \\
\hline & 0.13 & & 99 & 0.2 & 0.8 \\
\hline
\end{tabular}

A presença desse material grosseiro (areia) indica que o rio possue capacidade de transportar sedimentos grosseiros no fundo do canal. Ao pesquisar a essa geoforma deposicioanal pode-se verificar que essa está passando pelo processo de estabilização, pois em alguns pontos possuem presença de vegetação.

\section{Considerações Finais}

O rio Tapaiúna é afluente da margem esquerda do rio Teles Pires e encontra-se no municipio de Nova Canaã do Norte. Os sedimentos analisados demonstraram que este rio tem capacidade de transportar sedimentos grosseiros (fundo) contribuindo assim, para a carga de sedimentos do rio Teles Pires e formação de barras laterais e centrais no baixo curso do rio.

\section{Bibliografia}

ANDRADE, L. N. P. da S.; SOUZA, C. A. de. Sub-Bacia Hidrográfica do Córrego das Pitas: Análise Batimétrica e Transporte de Sedimentos. In: São Paulo, UNESP, Geociências, v. 28, n. 4, p. 387-400, 2009. Disponível em: http://www.revistageociencias.com.br/28_4/Art\%2004_Andrade.pdf Acesso em: 10 jan. 2017.

CAMARGO, L. (Org.) Atlas de Mato Grosso: Abordagem socioeconômica - ecológica. Cuiabá, MT: Entrelinhas, 2011. Cuiabá, MT: Entrelinhas, 2011.

CHRISTOFOLETTI, A. A Análise de Bacias Hidrográficas. In: Geomorfologia. 2ed.São Paulo: Blucher, 1980. p. 102-121.

BRASIL. Empresa Brasileira e Pesquisa Agropecuária - EMBRAPA. Manual de métodos de análises de solos. 2.ed. Rio de Janeiro: EMBRAPA solos, 1997. 212p. 
GIL. A. C. Métodos e técnicas de pesquisa social. 2. ed. São Paulo: Atlas, 2000.

GALVÃO, V.; STEVAUX, J. C.; SAAD, A. R. Análise Geoambiental dos Ambientes da Planície Aluvial do Alto Curso do Rio Paraná: Fragilidade e Impactos Ambientais Relativos ao Desenvolvimento do Uso Turístico. In: São Paulo, UNESP, Geociências, v. 33, n. 3, p.472-491, 2014. Disponível em: http://www.revistageociencias.com.br/33/volume33_3_files/33-3-artigo-9.pdf Acesso em: 10 jan. 2017.

POPP, J. H. Rios: Processos Fluviais e Aluviais. In: Geologia Geral. Rio de Janeiro: LTC, 2016. p. 161-182.

SILVA, A. M.; SCHUlZ, H. E.; CAMARGO, P. B. Hidrossedimentologia em Bacias Hidrográficas. In: Erosão e Hidrossedimentologia em Bacias Hidrográficas. São Carlos: RiMa, 2007. p. 105-135.

SOUZA, C. A. et al,. Bacia Hidrográfica do Rio Jauru e Seus Afluentes. In: SOUZA, C. A.; SOUZA, J. B. de.; ANDRADE, L. N. P. da S.(Org.). Bacia Hidrográfica do Rio Jauru - Mato Grosso: Dinâmica espacial e impactos associados. São Carlos: RiMa Editora, 2012. p. 01-28. 